\title{
A CACHAÇA ARTESANAL MINEIRA: INTERNACIONALIZAÇÃO E ALIANÇAS ESTRATÉGICAS
}

\author{
Henderson Márcio Gomes Domingos \\ Mestrando em Administração pela Fundação Pedro Leopoldo \\ e Professor da Faculdade ASA de Brumadinho.
}

Flávia Maria Coelho Baeta

Mestranda em Administração pela Fundação Pedro Leopoldo

Márcia Adriana Barbosa

Mestranda em Administração pela Faculdade de Pedro Leopoldo;

Professora da Faculdade da Cidade de Santa Luzia - FACSAL e

Universidade de Alfenas - UNIFENAS/Campus BH.

\section{INTRODUÇÃO}

Mudanças econômicas significativas têm se acelerado desde 1970 e, particularmente, a partir da década de 90. Uma das mais importantes mudanças é o processo de globalização. Este fenômeno envolve internacionalização, crescente instabilidade dos mercados, competição intensiva, baseada em qualidade, variedade e preços acessíveis. O processo de globalização da economia tem impulsionado diversas empresas brasileiras em direção ao mercado internacional e esta é uma realidade que surge inclusive para pequenas empresas.

As oportunidades são maiores porque o movimento em direção ao mercado livre abriu muitos mercados nacionais outrora protegidos. O potencial para exportação e para o investimento direto no exterior ampliou-se. $\mathrm{O}$ ambiente tornou-se mais complexo, pois as empresas têm deparado com novos desafios ao realizar negócios em países com culturas radicalmente diferentes e ao coordenar operações dispersas globalmente.

Esse fenômeno tem caracterizado um aumento da competição entre as empresas, à medida que economias nacionais abrem-se aos investimentos externos e novos concorrentes entram nos diferentes mercados (Oliveira et al, 1999).

A globalização não só exige presença nos mercados chaves, mas também aumento da produtividade, redução de custos, melhoria da qualidade dos produtos, investimentos na qualificação dos funcionários e desenvolvimento de novas tecnologias. Porém, em geral, o incremento da competitividade e a onipresença em diversos mercados são atividades muito onerosas para a maioria das empresas (Klotzle, 2002). Buscando adaptar-se a essa nova realidade, empresas, muitas delas concorrentes, têm recorrido a alianças como forma de viabilizar essa nova estratégia de internacionalização. 
Fabricantes de cachaça artesanal de Minas Gerais visualizaram no mercado internacional novas oportunidades e decidiram se unir para potencializar um processo de internacionalização. Este estudo pretende, portanto, compreender como tem ocorrido o processo de internacionalização desse grupo de empresas, com vistas às estratégias utilizadas.

\section{CONTEXTUALIZAÇÃO}

A cachaça artesanal ou de alambique de cobre é bebida tradicional brasileira, originária do século XVII, durante o ciclo histórico da cana-de-açúcar. Em 1988, a produção de cachaça em Minas Gerais recebeu uma importante alavancada para a elevação de seu padrão e qualidade.

Um grupo de destiladores de cachaça criou a AMPAQ - Associação Mineira dos Produtores de Cachaça de Qualidade, em parceria com o INDI - Instituto de Desenvolvimento Industrial de Minas Gerais. A AMPAQ dedica-se à pesquisa e disseminação de informações científicas e biotecnológicas, além de investir na definição de normas para regulamentação da produção do destilado da cana-de-açúcar em alambiques de cobre. Atualmente, tais normas são seguidas pelos 300 produtores filiados a essa associação.

O Estado de Minas Gerais é o líder brasileiro de produção de cachaça de alambique. Todo ano, são produzidos 150 milhões de litros desta bebida, por 8.500 pequenos produtores, representando 20.000 empregos diretos e 400.000 indiretos.

Em sintonia com a AMPAQ, e obedecendo às normas de qualidade exigidas para a certificação por meio do selo de garantia de qualidade, foi criada, em 1999, a Cooperativa da Cachaça COOCACHAÇA, centrada numa política de promoção e comercialização da cachaça de alambique.

Formou-se, também, em Minas Gerais, a Associação das Empresas Mineiras Exportadoras de Cachaça - COMEC. A associação é formada por 10 produtores de cachaça artesanal com elevado padrão de qualidade, que estão se organizando para internacionalizar seus produtos.

Enfim, a cachaça, que era um produto de consumo doméstico e culturalmente voltado às classes sociais mais baixas, vem mudando esse conceito de produto em direção a um mercado global.

\section{INTERNACIONALIZAÇÃO COMO ESTRATÉGIA}

\subsection{Internacionalização: conceito e modelos}

O termo internacionalização tem sido compreendido práticas das empresas voltadas para atividades externas às fronteiras do país de origem. Welch \& Luostarinen (1988) enriqueceram a definição, entendendo internacionalização como ações no sentido de ampliar o envolvimento das organizações em operações internacionais.

Beamish, citado por Coviello \& McAuley (1999), desenvolveu uma definição de internacionalização considerada por estes autores mais holística, considerando-a como um processo pelo qual as empresas ampliam o conhecimento em relação às influências diretas e indiretas das transações internacionais para o futuro, e estabelecem e conduzem transações com outros países. 
Primeiramente, a definição de Beamish integra a aprendizagem interna da organização em função de seus padrões de investimento. Segundo, ao considerar internacionalização como um processo, agrega ao conceito dinamismo e tendência evolucionária. Terceiro, a internacionalização não se restringe às exportações ou investimentos externos, ou seja, considera-se, também, internacionalizar para dentro do país-sede - importação. Finalmente, a definição reconhece que durante o processo de internacionalização, relacionamentos firmados por meio das transações podem influenciar a expansão da empresa em direção a outros países. Este estudo reconhece esta definição como mais apropriada para compreensão dos resultados alcançados.

Apesar dos estudos de internacionalização avançarem desde a década de 70 (Lamb \& Liesch, 2002), apenas recentemente, o debate teórico sobre internacionalização tem focado mais profundamente fatores específicos das pequenas empresas. A literatura clássica sobre o tema considera implicitamente as grandes empresas como objeto de análise. Entretanto, uma série de estudos tem enfatizado o tamanho como aspecto secundário para a competitividade externa das pequenas empresas, primeiro em função de sua crescente contribuição à balança comercial de seus respectivos países e, segundo, porque, na prática, as vendas externas desse nicho de empresas não têm sido afetadas pelo seu tamanho (De Chiara \& Minguzzi, 2002).

No entanto, barreiras apresentam-se no processo de internacionalização. Masurel (2001) identifica algumas: dificuldades na formação de parceiros externos, de competências e experiências gerenciais e de obtenção de informações.

Em função dessas barreiras, Johanson \& Wiedersheim-Paul (1988) identificam que o processo de internacionalização tende a ocorrer de forma incremental, isto é, como a lacuna de conhecimento sobre o mercado estrangeiro é um grande obstáculo ao processo, as empresas minimizam as dificuldades aprendendo gradativamente por estágios de internacionalização.

Como as firmas obtêm expertise, à medida que exercitam a internacionalização, acabam por buscar a expansão na forma de círculos concêntricos em direção aos países que são fisicamente e culturalmente mais distantes e passam a requerer maior alocação de recursos. A variável explanatória fundamental nos modelos de processo de internacionalização é o conhecimento experimental do mercado (Manolova et al, 2002).

Diversos estudos têm classificado diferentes tipos e estágios de internacionalização. Os estágios de internacionalização oferecem diferentes significados à alocação de recursos, e à geração de diferentes experiências e informações para as empresas no tocante ao mercado alvo. As empresas, à medida que se envolvem mais intensamente dentro dos estágios de internacionalização tendem a ampliar a alocação de recursos e o conhecimento sobre o mercado. Optou-se neste estudo pela classificação de Johanson \& Wiedersheim-Paul (1975) que distingue quatro estágios: atividades de exportação irregulares, exportação via representantes, vendas por subsidiárias e a transferência da produção para o país de destino. Para o estudo em questão o foco é o estágio de exportação.

A estratégia de exportação é adotada por muitas empresas de manufatura que iniciam sua expansão global. Exportar ajusta, no caso das pequenas empresas, suas competências ao oferecer um maior nível de flexibilidade e minimizar os recursos comprometidos, além de limitar a exposição da empresa aos riscos do negócio. Exportar pode ser ainda uma construção para o crescimento e aumento da lucratividade da empresa. Entretanto, no geral, há uma minoria de empresas correntemente engajadas em qualquer tipo de atividade de exportação. 
Os obstáculos à exportação, no tocante às pequenas empresas, surgem basicamente de três formas. Primeiramente, exportar a partir do país-sede da empresa pode não ser apropriado se os outros países oferecem custos locais para se fabricar o produto. Segundo, o processo de exportação pode ser economicamente inviabilizado ao gerar altos custos de transporte relacionados às deseconomias de escala. Enfim, os países-alvo da exportação podem impor barreiras alfandegárias insustentáveis ao processo.

Em um processo de internacionalização, além dos estágios, há que se considerar algumas dimensões específicas que interferem no seu resultado (Welch \& Luostarinen, 1988). Primeiramente, as empresas tendem a aprimorar o processo produtivo (know-how) para atender o mercado externo, principalmente no que diz respeito à qualidade e ao atendimento às normas ambientais. Segundo, à medida que as empresas se envolvem em operações internacionais, elas tendem a expandir sua atuação em profundidade - agregando valor - e diversidade - ampliando o mix, mudando o conceito de produto ou expandindo e criando linhas novas de produtos. Terceiro, há uma tendência primária das organizações em aproximar de mercados que oferecem maior simplicidade e similaridade no campo político, cultural e econômico, além de menor custo de acesso.

Outra dimensão a considerar é a estrutura organizacional ${ }^{i}$ influenciando na definição do grau de internacionalização da empresa. A estrutura organizacional claramente definida permite maior previsibilidade das ações, pois as tarefas, a autoridade e a responsabilidade estão devidamente alocadas. Neste sentido, os recursos humanos envolvidos no processo, também, interferem sensivelmente no início e manutenção dos estágios de internacionalização. A função recursos humanos é, particularmente, crítica para a implementação de joint ventures, licenciamentos ${ }^{\mathrm{ii}} \mathrm{e}$ projetos de cooperação, com resultados positivos. Pessoal treinado e com a visão para o mercado permite melhor padronização dos processos e manutenção dos critérios de qualidade exigidos pelo mercado externo.

Particularmente, estudos indicam que habilidades gerenciais e percepções do ambiente são as mais importantes dimensões de capital humano. Espera-se que empreendedores ou executivos com experiência em atividades internacionais ou detentores de rede de relacionamentos pessoais fortes tendem a possuir habilidades necessárias para a condução de negócios internacionais. Consistente com esse argumento, acredita-se que empreendedores ou executivos com percepções positivas do ambiente internacional tendem a ser mais desejosos pela internacionalização de seus próprios negócios (Pope, 2002).

Por fim, o avanço do processo de internacionalização tende a ampliar a demanda por recursos financeiros. A natureza e a extensão das atividades financeiras das empresas voltadas para as operações internacionais são indicadores do grau de internacionalização.

Com o objetivo de tornarem sólidas as dimensões citadas, as pequenas empresas têm procurado associarem-se. Compreendendo a importância dessas alianças formadas, Rezende (2002) reforça que os processos de internacionalização podem ser explicados por relacionamentos desenvolvidos (...). Estes relacionamentos são usualmente construídos de maneira incremental à medida que os atores ajustam expectativas, mudam atitudes e ampliam suas bases de conhecimento com o decorrer do tempo. 


\subsection{Alianças estratégicas: classes e modelos}

Klotzle (2002) salienta a inexistência de definições universalmente aceitas sobre o que constitui uma aliança estratégica. No entanto, Teece (1992) desenvolveu conceito mais abrangente. Alianças estratégicas seriam acordos nos quais dois ou mais parceiros dividem o compromisso de alcançar um objetivo comum, agregando capacidades e recursos e buscando coordenação das atividades. Uma aliança estratégica implica, muitas vezes, em operações diversas como: atividades conjuntas de Pesquisas e Desenvolvimento, transferência mútua de tecnologia, concessão de direitos exclusivos de produção e venda e acordos de cooperação na área de marketing. Alianças estratégicas podem ou não envolver participação acionária.

Lorange \& Roos (1996) ampliam o conceito e classificam as alianças estratégicas em: comprometidas em longo prazo, cooperação baseada em projeto e cooperação baseada em investimento de capital a longo prazo. A partir desta classificação, pode-se distribuir as alianças estratégicas em negócios internacionais, com base na teoria do custo de transação, em um continuum/escala, conforme figura 1:

O lado esquerdo da escala representa a integração total das atividades dentro da organização. Arranjos de propriedade conjunta podem representar um grau menor de integração. Vários tipos de empreendimentos cooperativos formais e informais representam etapas ao longo do caminho em direção a níveis ainda menores de integração vertical. Ao final do lado direito da escala contínua encontra-se o mercado em que se é livre para trocar bens e serviços. Não há qualquer integração vertical. As alianças estratégicas podem ser definidas como empreendimentos de risco ao longo dessa escala. Da esquerda para direita da escala, apresentam-se as seguintes opções: fusões e aquisições, participação societária, joint venture, empreendimento cooperativo formal e empreendimento cooperativo informal.

Lorange \& Roos (1996) identificam uma outra forma de caracterizar as alianças estratégicas com base em quatro modelos fundamentados nos seguintes aspectos: como são alocados os recursos, qual é o tipo de relação existente entre os atores e de que forma são avaliados os resultados da aliança.

Os modelos de alianças são: a aliança provisória, a aliança estratégica do tipo consórcio, joint venture baseada em projetos e joint venture plena. Tem-se uma aliança provisória ou acordo provisório quando as empresas-mãe alocam poucos recursos, de maneira temporária, buscando finalmente o seu retorno integral. A relação é estabelecida entre uma grande e uma pequena empresa. Dessa forma, é importante examinar a compatibilidade de recursos, as tecnologias e os outros recursos necessários. É estratégico, também, antecipadamente, definir a distribuição das tarefas. Os resultados da aliança provisória são medidos pelo alcance dos objetivos como desenvolvimento de uma tecnologia específica ou conquista de um novo segmento de mercado. Os objetivos sendo alcançados, a aliança tende a se extinguir.

Nas alianças estratégicas do tipo consórcio, os recursos são, geralmente, mais volumosos e diversificados, o que permite maior flexibilização em direção a novas oportunidades. Espera-se que os recursos gerados retornem a todos os atores. Neste caso, a relação entre os envolvidos é de paridade. A idéia é considerar que parceiros iguais devem criar a base para uma posição ganhaganha evitando-se qualquer possível situação de enfrentamento. Sendo assim, deve-se buscar total cooperação, tentando evitar a duplicação de esforços, utilizar recursos complementares e ser realista sobre como os recursos individuais podem ser mais bem utilizados.

Os resultados dos consórcios são avaliados quanto ao alcance das metas como o desenvolvimento de um novo produto ou a penetração em mercado específico. Os indicadores de desempenho podem 
ser estabelecidos por meio da relação custo-benefício e pela alocação de recursos de forma uniforme por parte de todos os atores.

Lorange e Roos (1996) caracterizam joint ventures baseadas em projeto, aquelas que surgem de baixo investimento das partes, porém os resultados permanecem mantidos no negócio, ou seja, os parceiros mantêm a aliança. As atividades oriundas desta parceria, normalmente, são compreendidas como negócio periférico dos envolvidos. O desafio da aliança passa a ser a conciliação das percepções das partes, considerando que possuem vantagens diferentes e devem estabelecer um entendimento comum. Em geral, os envolvidos agregam vantagens competitivas diferenciadas ao negócio, como por exemplo, um participa com vantagem tecnológica e o outro com market-share.

O receio relativo às alianças tipo joint venture baseada em projeto é, no íntimo dos aliados, estar expondo suas forças e fraquezas. O desenvolvimento de um plano de negócio trata do estabelecimento da base para os complementos entre as duas partes, documentando que a aliança estratégica pode ser competitiva no mercado em análise. Quanto à avaliação dos resultados, os indicadores de vendas e de lucratividade são relevantes, além de identificar se a aliança mantém-se competitiva.

Por fim, a aliança estratégica do tipo joint venture plena, segundo Lorange \& Roos (1996), são aquelas que exigem maior liberdade de alocação de recursos por parte dos envolvidos e os recursos gerados tendem a ser mantidos na aliança estratégica dando sustentação para mobilizações estratégicas futuras. O negócio em questão, normalmente, é relativamente periférico para ambos. A ênfase é aumentar a sinergia, por meio da utilização conjunta de esforços.

O desafio da joint venture plena passa a ser como que as partes envolvidas saem do negócio, a partir do momento da reestruturação das atividades do novo negócio, e, também, proporcionar a disseminação da idéia que a cooperação é a única maneira realista para o estabelecimento de uma aliança estratégica. Sendo assim, ambas as partes devem estar inclinadas a empregar todos os esforços de que dispõem. Portanto, a participação intensiva da alta administração passa a ser imprescindível. A mensuração do negócio foca-se no desenvolvimento de indicadores voltados para a identificação do market-share, da qualidade e da satisfação do cliente.

\section{METODOLOGIA}

Como o objetivo do estudo é estar identificando como tem ocorrido o processo de internacionalização da cachaça artesanal ou de alambique em Minas Gerais, optou-se por utilizar duas organizações que têm como missão viabilizar este processo: a COMEC e a COOCACHAÇA.

O método de pesquisa é o estudo de caso, ao focalizar dois grupos mineiros específicos de fabricantes de cachaça artesanal. A pesquisa, quanto aos fins, passa a ser exploratória, no sentido, de estar buscando identificar quais as estratégias utilizadas para responder aos desafios impostos pelo processo de internacionalização das empresas.

O instrumento de coleta de dados é o de entrevista semi-estruturada, por meio do qual define-se um roteiro básico de entrevista e, a partir deste o entrevistador pode está enriquecendo o conteúdo no desenrolar do levantamento. O roteiro de entrevista desenvolve-se com base na análise do referencial teórico. As questões pré-definidas abrangem informações sobre as mudanças estruturais, 
culturais, nas práticas e políticas gerenciais e a preocupação na qualificação da mão-de-obra das empresas frente às transformações decorrentes do processo de internacionalização.

Em relação a escolha da amostra, a definição dos entrevistados é quanto à acessibilidade, ou seja, a entrevista se dá com parte dos proprietários dos alambiques envolvidos, especialmente, se possível, com aqueles que coordenam diretamente o processo.(VERGARA, 1998).

Foi entrevistado o presidente, que é um dos fundadores da COMEC, Sr. Márcio Vieira de Moura.

Portanto, é um dos participantes de todo o processo de formação do consórcio e da associação.

Quanto ao COOCACHAÇA, não foi possível o agendamento de entrevistas, tendo como alegação de seus diretores o sigilo das informações. Porém, viabilizou-se agregar algumas informações à pesquisa por meio do site da cooperativa.

Para complementação do estudo foi enviado um questionário com seis perguntas abertas, via email para o Presidente da AMPAQ, Sr. Luiz Cláudio P. Cury.

\section{A BUSCA DO MERCADO INTERNACIONAL: O CASO}

A formação da COMEC deu-se gradativamente, de forma que as dez empresas envolvidas pudessem aumentar sua expertise em internacionalização. Primeiro, os empresários procuraram desenvolver o conhecimento sobre internacionalização, por meio de uma parceria com uma instituição de ensino - Centro Universitário Newton Paiva - que preparou treinamentos específicos da temática. Conjuntamente com os treinamentos, eles reuniam-se na busca de consolidar um modelo pelo qual estariam alcançando o mercado internacional.

A idéia de consórcio parecia a mais provável. Apesar de saberem que o modelo de consórcio compreende uma parceria, baseada em cooperação mútua e junção de esforços para evitar sua duplicação, tiveram que repensar o modelo, pois a legislação brasileira não reconhece este tipo de organização.

Concomitantemente à definição do modelo, estudos são desenvolvidos no sentido de criar as condições de competitividade do produto no mercado. Dessa forma, em parceria com outra instituição de ensino - CEFET/MG - tem sido construído um modelo de gestão da qualidade, traçando princípios que nortearão o planejamento do negócio como missão e objetivos. Têm sido desenvolvidas pesquisas para criar uma certa padronização nos processos, para melhor aproveitamento dos recursos, ou seja, identificar a melhor espécie de cana-de-açúcar para determinado solo, melhor momento para a colheita, processo mais correto de moagem que propicie a otimização no aproveitamento do açúcar da cana. Enfim, buscar o método adequado para cada etapa do processo produtivo. Observa-se, então, que a ênfase é em produtividade, atuando sobre o processo e qualidade em relação à gestão.

No tocante ao controle da qualidade do produto a ênfase é em sua implementação por todo o processo finalizando com a inspeção final ao executar as conferências físico-química e sensorial. Segundo Sr. Luiz Cláudio, Presidente da AMPAQ, o processo de internacionalização não implica em melhoria da qualidade do produto, pois é um lema de seus associados seja para o mercado externo, seja para o mercado interno. A única mudança observada é quanto ao teor alcoólico, que deve ser $40 \%$ GL, devido a questões tributárias. 
A COMEC, que apesar de, legalmente, não ser habilitada a exercer atividades comerciais, por seu caráter associativo, tem contribuído para o debate e coordenação do processo de internacionalização das empresas associadas. Sua formação permitiu a alavancagem de recursos financeiros por meio da APEX, para a implementação do projeto elaborado pelo CEFET/MG.

O projeto implicou no estabelecimento de princípios a serem seguidos pelos associados, que, por outro lado, funcionam como critérios para a entrada de novos componentes. Primeiro, o associado ou pretendente deve ser produtor de cachaça de qualidade. Segundo, ele deve possuir a capacidade de trabalhar em equipe. Terceiro, precisa ter internalizado o desejo de desenvolvimento contínuo e de exportação. Como último critério, deve ter a aceitação do grupo. É importante salientar que um novo componente somente passa por estes critérios de avaliação se for indicação de um associado.

Compreendido que as estratégias de consórcio e associação não viabilizam comercial e operacionalmente o processo de internacionalização e que o sistema de cooperativa é destinado a pessoas físicas, a opção em desenvolvimento pelos dez empresários tem sido a criação de uma empresa, aproximando-se do modelo de joint venture plena, a ser constituída até janeiro de 2003. Como o negócio de exportação é considerado periférico, a princípio pelos integrantes da associação, visto que eles permanecem com suas atividades anteriores e estariam aproveitando para exportação uma sobra de produção existente, atualmente utilizada para venda no mercado interno a baixo custo, os associados seriam ao mesmo tempo sócios e fornecedores do novo empreendimento. Com esta nova organização, a participação do grupo continuaria intensa na alta administração do novo negócio.

O novo empreendimento é o meio empregado para dar forma à idéia inicial e que está em desenvolvimento: a criação de uma marca de cachaça comum para o novo empreendimento, visto que o custo de exportação das dez marcas inviabilizaria o negócio. O novo produto será um blend, ou seja, a mistura das dez marcas da associação. Já escolheu o local onde as marcas seriam misturadas - um dos associados, devido sua estrutura física. A nova empresa terá um gerente de negócios, que administrará todas as atividades do empreendimento. Pretende-se, enfim, uma nova estrutura organizacional independente da estrutura dos alambiques, porém organizada de forma simplificada. A estrutura enxuta prevista inicialmente é decorrência da visão do crescimento gradativo previsto pela a Associação.

A definição do segmento de mercado caracteriza, também, o direcionamento a ser dado ao projeto. Segundo Sr. Márcio, o novo produto está direcionado a "pessoas que gostam de produtos de ecológicos, naturais, culturais, artesanais e de qualidade". A nova marca de cachaça compreende estes conceitos, visto que é ecológico, pois, principalmente na formação dos canaviais, não se utilizam queimadas; é natural pela sua origem vegetal; é cultural, pois não deixa de ser uma bebida tradicional brasileira; é de qualidade, pois esta preocupação vem desde a seleção dos associados até às pesquisas feitas para melhoramento da cachaça e; é artesanal, pois a forma de produção por alambique, que é centenária, permanece.

Escolheu-se, como mercados externos iniciais neste processo de exportação, a Alemanha e Portugal. Segundo Sr. Márcio, estes países são os maiores importadores de cachaça. Sendo assim, o esforço de introdução do produto tende a ser menor, pois o mercado já conhece a cachaça. O trabalho mercadológico estaria voltado com maior intensidade, então, para a fixação da marca. Os contatos estabelecidos com as Câmaras de Comércio desses dois países, também, influenciaram na escolha desses mercados. 
A aprovação dos novos padrões de produção desenvolvidos pelo CEFET/MG está prevista para o mês de junho de 2002. A partir deste momento, serão feitos treinamentos com os alambiqueiros (trabalhador responsável por acompanhar a produção da cachaça) dos dez associados, que se encontrarão em uma unidade específica para o processo de aprendizagem.

Quanto à COOCACHAÇA percebeu que a sua formação está centrada na promoção e comercialização da cachaça artesanal para exportação em quantidades crescentes. A missão da entidade engloba desenvolver e aprimorar a qualidade sensorial do produto, preservar as tradições culturais baseadas em exploração equilibrada do meio ambiente, capacitação profissional e em disseminação de tecnologia para a expansão da produção. A preocupação com o retorno justo aos cooperados é, também, perceptível nesta missão.

\section{CONCLUSÃo}

Identificaram-se duas opções de modelo de aliança para o processo de internacionalização. Por um lado, tem-se um sistema cooperativo formal adotado pela COOCACHAÇA. Por outro lado, verifica-se um sistema cooperativo formal (associativo) direcionado à formatação das estratégias de exportação, que caminha para a formação de uma empresa autônoma para viabilizar as operações comercias.

Ambas estruturas demonstram preocupação com o aprimoramento do processo produtivo, ou seja, do know-how, capacitação dos recursos humanos e com a adequação da imagem do produto voltada à preocupação ambiental e cultural. Isto significa estar buscando um novo conceito ao produto cachaça, ampliando seu valor agregado.

No entanto, a preocupação com o desenvolvimento das habilidades gerenciais e a ampliação das percepções sobre o mercado internacional só pode ser possível verificar, pelo acesso a informações, na COMEC, que desde o início da proposta de internacionalização tem buscado conhecimento técnico de como alcançar o mercado externo com o apoio de instituições de ensino superior.

Quanto ao aspecto estrutural, identifica-se, no caso da COMEC, a formação de uma nova estrutura para viabilizar o negócio. O site da COOCACHAÇA não fornece informações da estrutura da Cooperativa e de como ela operacionaliza.

Os resultados da COOCACHAÇA perante às exportações não foram, também, divulgados. Porém, pelo lado da COMEC, percebe a engenhosidade do negócio, a rede de relacionamentos estabelecida e o entusiasmo na implementação das etapas do processo de internacionalização. Verifica-se que a Associação segue toda uma cartilha: pesquisar sobre internacionalização, somar esforços, implementar um modelo de gestão da qualidade, rever processos e padronizar procedimentos, capacitar pessoal (gerencial e operacional) e viabilizar mecanismos mais viáveis e legalmente aceitos para alcançar o mercado internacional.

No entanto, a contribuição de novos trabalhos posteriores seria verificar o sucesso ou fracasso do empreendimento e os impactos sobre os trabalhadores na sua relação com os fabricantes, considerando que estariam em contato permanente entre si em treinamentos para uniformização dos processos. Isto poderia implicar em demandas salariais e por novos benefícios. 


\section{REFERÊNCIAS BIBLIOGRÁFICAS}

BEAMISH, P. W. The internationalization process for smaller ontario firms: a research agenda. In: RUGMAN, A. M. (Ed.). Research in global strategy management - international business research for the twenty-first century: Canada's new research agenda. Greenwich: JAI Press Inc., 1990. p. 92.

COOPERATIVA DA CACHAÇA. Disponível em: <http:/www.coocachaca.com.br> Acesso em 20 maio 2002.

COVIELLO, Nicole E.; McAULEY, Andrew. Internationalization and the smaller firm: a review of contemporary empirical research. Management International Review, Wiesbaden. Third Quarter 1999.

DE CHIARA, Alessandra.; MINGUZZI, Antônio. Sucess factors in SME internationalization processes: an italian investigation. Journal of Small Business Management, Milwaukee. April. 2002.

JOHANSON, Jan J.; WIEDERSHEIM-PAUL, Finn. The internationalization of the firm: four swedish case. Journal of Management Studies, October:/1975: 305-22.

KLOTZLE, Marcelo Cabus. Alianças estratégicas: conceito e teoria. Revista de Administração Contemporânea, São Paulo, v. 6, n. 1, p. 85-104, jan./abr. 2002.

KOGUT, Bruce. Joint ventures: theoretical and empirical perspectives. Strategic Management Journal, vol. 9, 1988. p. 319-32.

LAMB, Peter W.; LIESCH, Peter W. The internatiolization process of the smaller firm: Re-framing the relationships between market, commitment, knowledge and involvement. Management International Review, Wiesbaden. First Quarter 2002.

LORANGE, Peter.; ROOS, Johan. Alianças estratégicas: formação, implementação e evolução. São Paulo: Atlas, 1996.

MANOLOVA, Tatiana S. et al. Internationalization of small firms: personal factors revisited. International Small Business Journal, London., fev. 2002.

MASUREL, Enno. Export behavior of service sector SMEs. International Small Business Journal, London, jan./mar. 2001.

OLIVEIRA, Virgínia I.; DRUMMOND, Aldemir.; RODRIGUES, Suzana.; B. Joint venture: aprendizagem tecnológica e gerencial. In: Competitividade, alianças estratégicas e gerência internacional. RODRIGUES, Suzana B. (org.). São Paulo: Atlas. 1999.

POPE, Ralph A. Why small firms export: another look. Journal of Small Business Management, Milwaukee, jan. 2002.

REZENDE, Sérgio. Gradualismo e descontinuidade em processos de internacionalização (aprovado para publicação na RAUSP - Revista de Administração da USP. 2002). 
TEECE, D. J. Competition, cooperation and innovation: organizational arrangements for regimes of rapid technological progress. Journal of Economic Behavior and Organization, v. 18, 1992.

VERGARA, Sylvia Constant. Projetos e relatórios de pesquisa em administração. São Paulo: Atlas, 2000.

WELCH, Lawrence S.; LUOSTARINEN, Reijo. Internationalization: evolution of a concept. Journal of General Management, 1988. Vol. 14/2: 34-64.

\section{NOTAS}

\footnotetext{
${ }^{\mathrm{i}}$ Estrutura organizacional refere-se ao modo como as atividades de uma organização são divididas, organizadas e coordenadas. Implica na divisão do trabalho e na departamentalização.

${ }^{\text {ii }} \mathrm{O}$ licenciamento internacional é um arranjo pelo qual o licenciado em outro país compra os direitos de fabricação do produto da empresa em seu próprio país por uma taxa negociada. O licenciado então investe a maior parte do capital necessário para manter as operações estrangeiras funcionando.
} 